\title{
UTILIZAÇÃO DE RESÍDUO DE MADEIRA PINUS COMO AGREGADO PARA
}

\section{PRODUÇÃO DE BLOCOS DE CONCRETO}

USE OF WOOD WASTE PINUS AS AGGREGATE FOR PRODUCTION OF CONCRETE

BLOCKS

Karina Kreidlow ${ }^{1}$

Maicon Anderson de Souza ${ }^{2}$

\section{RESUMO}

A construção civil é um dos mercados que mais geram resíduos, cerca de $60 \%$ do volume total dos resíduos gerados nas cidades brasileiras. Devido a esta preocupação referente à geração de resíduos sólidos, foram desenvolvidos estudos visando adequar a destinação dos resíduos gerados, na qual se produziu diversos blocos de concreto, utilizando como agregado os resíduos de madeira Pinus, verificando em laboratório a resistência do mesmo, consequentemente disponibilizando uma destinação mais nobre que a combustão. Os blocos de concreto utilizando agregado de madeira de pinus podem ser utilizados em alvenaria estrutural, mesmo que seja matéria orgânica seu desempenho em relação à resistência é satisfatório. Portanto, a construção civil deve utilizar as tecnologias a seu favor, com a utilização dos resíduos sólidos disponibilizando uma destinação adequada, de modo que retorne ao mercado com alta qualidade para ser utilizado novamente.

Palavras-Chave: Blocos de concreto. Madeira Pinus. Serragem. Resistência.

\section{INTRODUÇÃO}

A produção de blocos de concreto normalmente utiliza aglomerante, agregados graúdos e miúdos, água e eventualmente aditivos e corantes. Contudo, será substituído parcialmente o agregado miúdo pelo resíduo de Pinus obtendo

\footnotetext{
${ }^{1}$ Centro Universitário de Brusque - UNIFEBE. E-mail: karinakreidlow@unifebe.edu.br.

${ }^{2}$ Centro Universitário de Brusque - UNIFEBE.
} 
resultados satisfatórios permitindo sua utilização.

Medidas foram criadas para melhoramento da principal desvantagem, sendo a incompatibilidade química entre o cimento e a madeira. A madeira na sua composição química apresenta açúcares, resinas, fenóis e amidos que interferem de maneiras diversas a hidratação do cimento.

A norma brasileira NBR 6136 define os blocos vazados como componentes de alvenaria com área líquida igual ou inferior a $75 \%$ da área bruta. Entretanto, esta norma classifica os blocos quanto a sua resistência definindo seu uso quanto ao estrutural ou alvenaria (ABNT, 2008).

\section{MATERIAIS E MÉTODOS}

\section{MATERIAIS UTILIZADOS}

O aglomerante utilizado na pesquisa foi o cimento Portland tipo CP II-F-32 da marca Itambé, sendo apresentado na NBR 11.578 como cimento Portland composto com fíler (ABNT, 1991).

O resíduo de Pinus utilizado para substituir parcialmente o agregado miúdo, é caracterizado como serragem, proveniente do desdobro de toras de madeira Pinus, com idades variadas, obtida em uma Madeireira no bairro Águas Claras, Brusque, SC. Posteriormente a coleta, a serragem foi seca ao ar livre e peneirada, com objetivo de obter uma granulometria máxima de $4,75 \mathrm{~mm}$, conforme NBR NM 248 (ABNT, 2003).

Aditivo utilizado é o superplastificante de pega normal, sendo produtos isentos de cloretos, disponibilizando maior consistência e trabalhabilidade na massa, consequentemente reduzindo o consumo de água sem afetar o tempo de pega.

No Brasil, é difundido o uso de agentes tensoativos (detergentes, sabão) na produção de blocos de concreto, sem que tenha uma razão técnica para esta prática (MEDEIROS, 1993).

METODOLOGIA

Para um estudo preliminar, foram produzidos duas séries de blocos, sendo 
uma série contendo dois blocos produzidos normalmente, sem a presença de agregado de Pinus na mistura e, a outra série composta também de dois blocos com substituição do agregado miúdo por resíduo de Pinus.

Os blocos de concreto foram produzidos no dia 02 de novembro de 2016, em uma máquina vibroprensa manual, aplicando uma carga unidirecional vertical durante a compressão do concreto fresco, produzindo cerca de quatro blocos por vez. A quantidade de água utilizada na massa foi definida visualmente, pela mão de obra local pela facilidade da moldagem dos blocos.

No Brasil, encontram-se usinas com equipamentos automatizados de alta produtividade e pequenas centrais onde funcionam betoneiras e vibroprensa operadas manualmente. Estes blocos produzidos com condições tão variadas apresentam propriedades desuniformes. Mas para uma produção uniforme, adotam-se medidas de prevenção como controle de fornecimento, melhorias na dosagem e controle sistemático no processo de cura dos blocos (MEDEIROS, 1993).

O processo de cura dos blocos de concreto, diferentemente de outros artefatos de cimento é muito delicado devido às condições extremas de sua dosagem. Utilizam-se quantidades mínimas de cimento e água para a fabricação, mas exigindo constante presença de água garantindo que ocorram completamente todas as reações do cimento (MEDEIROS, 1993).

Entretanto, para o ensaio de compressão utilizou-se proporções diferentes de agregados apresentando massa unitária compactada diferente, consequentemente índices de vazios variados. De acordo com as Tabelas 1 e 2, apresentam as especificações para cada traço da série de blocos produzidos sem resíduo da madeira Pinus, sendo indicado as quantidades para cada betoneira de $120 \mathrm{~L}$ efetuado somente para fins de estudo.

\begin{tabular}{c|c}
\hline \multicolumn{2}{|c}{ Traço 01 } \\
\hline Materiais & Massa $(\mathrm{Kg})$ \\
\hline Cimento Portland & 8,0 \\
\hline Água & - \\
\hline Pó de Brita & 105,96 \\
\hline Brita 0 & 105,96 \\
\hline
\end{tabular}

Tabela 1: Traço bloco 01 sem resíduos de madeira

Fonte: Própria do autor.

Ignis | Caçador | v.6 | n.2 | p. 35-46 | maio/ago. 2017 


\begin{tabular}{c|c}
\hline \multicolumn{2}{|c|}{ Traço 02 } \\
\hline Materiais & Massa $(\mathrm{Kg})$ \\
\hline Cimento Portland & 8,0 \\
\hline Água & - \\
\hline Pó de Brita & 158,94 \\
\hline Brita 0 & 52,98 \\
\hline
\end{tabular}

Tabela 2: Traço bloco 02 sem resíduo de madeira

Fonte: Própria do autor.

Conforme os traços apresentados anteriormente de forma a ilustrá-los, segue as Figuras 1 e 2 respectivamente.

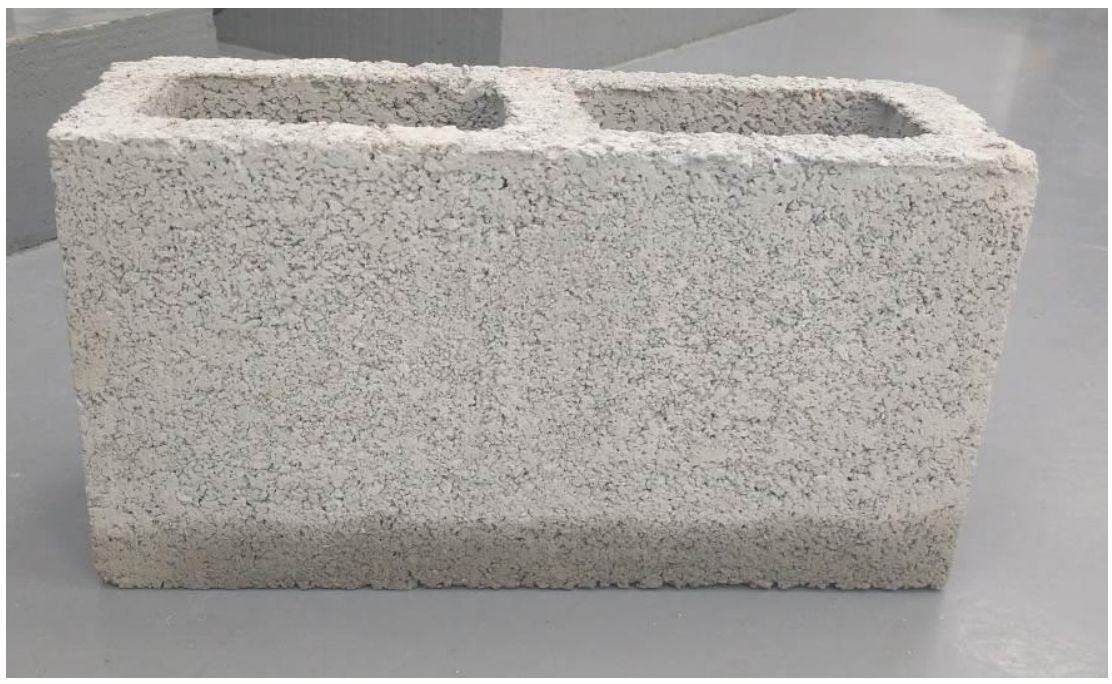

Figura 1: Bloco correspondente ao Traço 01

Fonte: Própria do autor. 


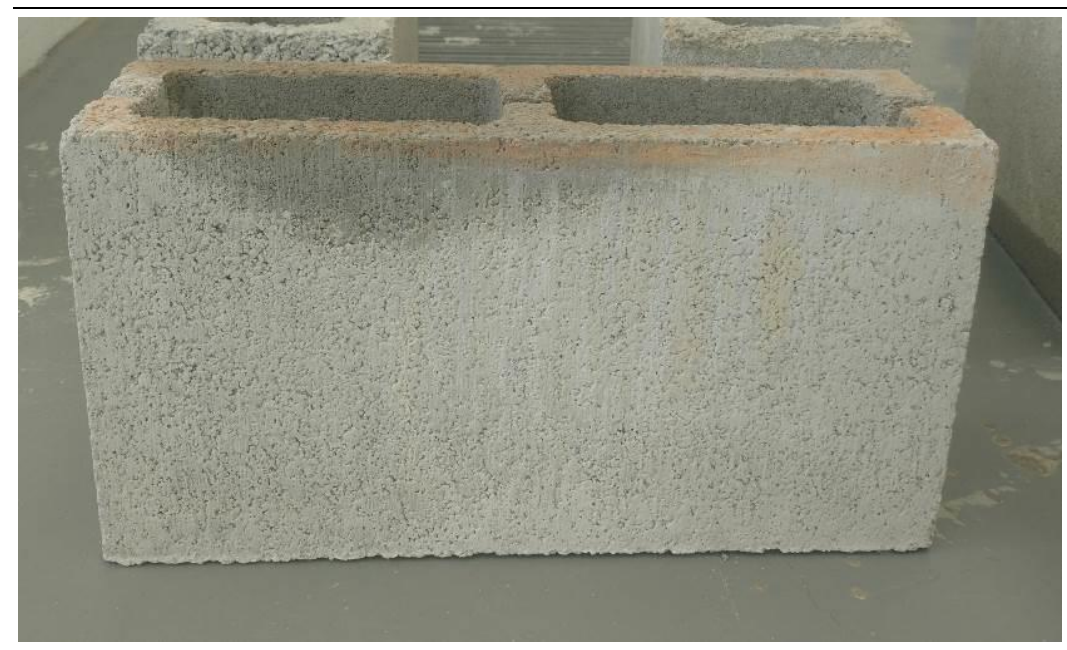

Figura 2: Bloco correspondente ao Traço 02

Fonte: Própria do autor.

Para a produção dos blocos utilizando o resíduo de madeira foi de modo in natura, ou seja, sem tratamentos ou aditivos, formando uma série de blocos com traços diferentes conforme as Tabelas 3 e 4 .

\begin{tabular}{c|c}
\hline \multicolumn{2}{|c}{ Traço 01 } \\
\hline Materiais & Massa $(\mathrm{Kg})$ \\
\hline Cimento Portland & 8,0 \\
\hline Água & - \\
\hline Pó de Brita & 105,96 \\
\hline Brita 0 & 52,98 \\
\hline Serragem Pinus & 21,20 \\
\hline
\end{tabular}

Tabela 3: Traço bloco 01 com resíduo de madeira

Fonte: Própria do autor.

\begin{tabular}{c|c}
\hline \multicolumn{2}{|c|}{ Traço 02 } \\
\hline Materiais & Massa $(\mathrm{Kg})$ \\
\hline Cimento Portland & 8,0 \\
\hline Água & - \\
\hline Pó de Brita & 105,96 \\
\hline Brita 0 & 52,98 \\
\hline Serragem Pinus & 42,40 \\
\hline
\end{tabular}

Tabela 4: Traço bloco 02 com resíduo de madeira 
Fonte: Própria do autor.

Conforme os traços apresentados anteriormente de forma a ilustrá-los, segue as Figuras 3 e 4 respectivamente.

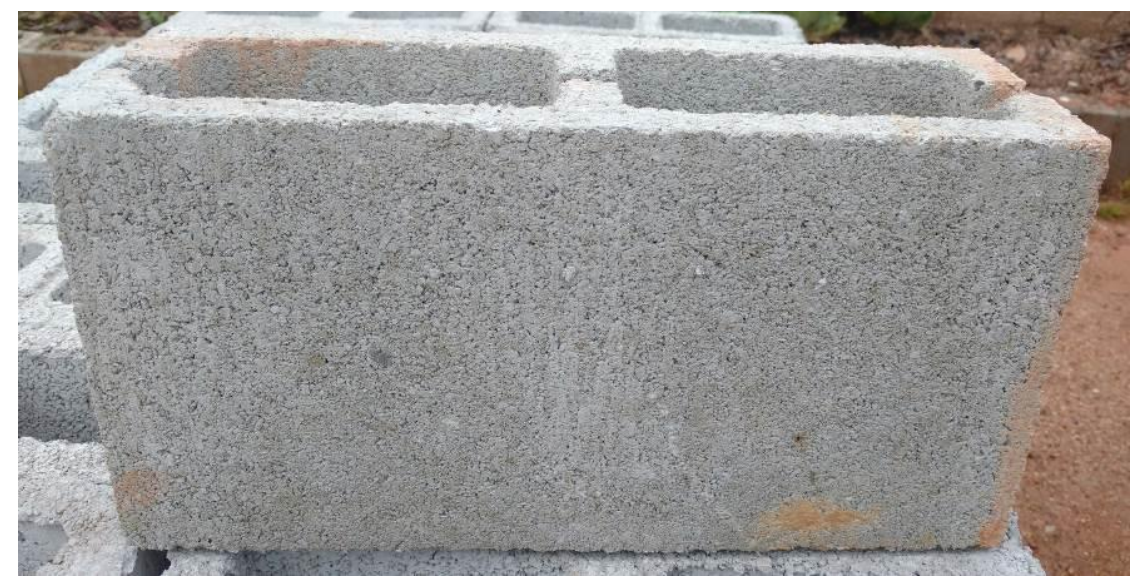

Figura 3: Bloco correspondente ao traço 01 com resíduo de madeira

Fonte: Própria do autor.

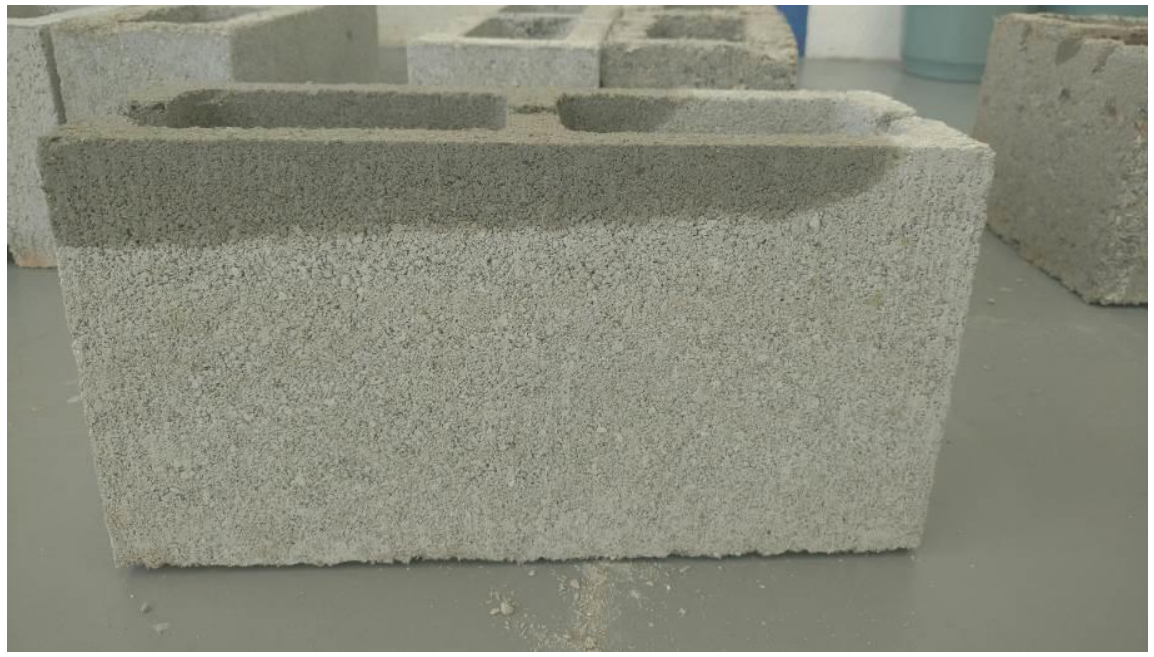

Figura 4: Bloco correspondente ao traço 02 com resíduo de madeira

Fonte: Própria do autor.

O ensaio de compressão foi feito no laboratório do Centro Universitário de Brusque - UNIFEBE, no dia primeiro de dezembro de 2016 obtendo os blocos com 29 dias de cura, alcançando sua resistência máxima. Juntamente com o acompanhamento de um professor orientador e um auxiliar de laboratório, executou-se o ensaio de duas amostras de cada traço obtendo uma média. 


\section{RESULTADOS E DISCURSÃO}

Conforme ensaio executado em laboratório, as Tabelas 7 e 8 apresentam os resultados obtidos por cada traço.

\begin{tabular}{|c|c|}
\hline \multicolumn{2}{|c|}{ Blocos sem resíduo de madeira } \\
\hline Protótipo utilizado & $\begin{array}{c}\text { Resistência a } \\
\text { compressão (Mpa) }\end{array}$ \\
\hline Traço 01 & 6,31 \\
\hline Traço 02 & 10,25 \\
\hline
\end{tabular}

Tabela 5: Resultados de resistência da série de blocos sem resíduos de madeira Fonte: Própria do autor.

\begin{tabular}{c|c|}
\hline \multicolumn{2}{|c|}{ Blocos com residuo de madeira } \\
\hline Protótipo utilizado & $\begin{array}{c}\text { Resistência a } \\
\text { compressão (Mpa) }\end{array}$ \\
\hline Traço 01 & 5,77 \\
\hline Traço 02 & 5,33 \\
\hline
\end{tabular}

Tabela 6: Resultados de resistência da série de blocos com resíduos de madeira Fonte: Própria do autor.

De acordo com análises nas tabelas anteriores, em relação às composições obtemos uma média satisfatória nos resultados. No traço com a presença de resíduos de madeira, observamos semelhança na resistência ao traço 01 contendo maior quantidade de brita 0 sem que tenha resíduo de madeira. Entretanto, no traço 02 com maior quantidade de pó de brita obtemos uma resistência maior, devido ao maior grau de compactação e eliminação de vazios na mistura.

Portanto, os blocos com utilização de resíduos de madeira apresentam maior absorção de água, ou seja, obtendo uma relação água/cimento maior. De acordo com a NBR 6136, podemos fazer uma breve classificação quanto sua resistência, conforme apresentado na tabela 7 abaixo.

\begin{tabular}{c|c|c}
\hline Classe & Traços dos blocos & Descrição \\
\hline Classe A & Traço 01 e 02 sem residuo de madeira & Com função estrutural acima e abaixo do nivel do solo \\
\hline Classe B & Traço 01 e 02 com residuo de madeira & Com função estrutural acima do nivel do solo \\
\hline
\end{tabular}

Tabela 7: Classificação conforme NBR 6136 utilizando sua resistência obtida

Fonte: Própria do autor.

Ignis | Caçador | v.6 | n.2 | p. 35-46 | maio/ago. 2017 
Observamos que os resultados obtidos são satisfatórios conforme o esperado, mesmo nos casos utilizando o resíduo de madeira, mas deve adotar medidas quanto à utilização dos blocos em paredes externas por possuir presença de matéria orgânica.

Apesar das resistências obtidas, os blocos após seu ensaio apresentou somente fissuras superficiais, sendo retirado do equipamento sem seu rompimento aplicando força nos locais com patologias, mas sem sucesso de colapso dos blocos. Conforme apresentado nas Figuras 5, 6 e 7 a seguir, patologias encontradas após ensaio de alguns protótipos.

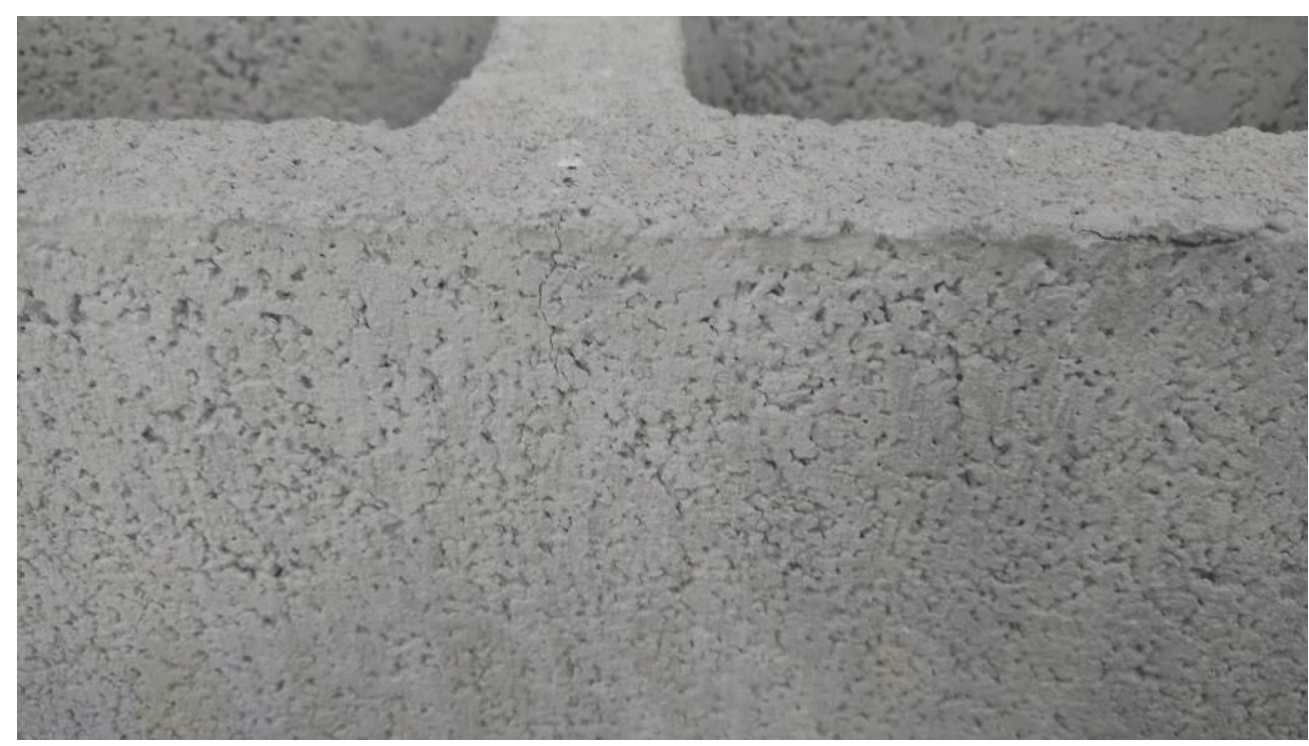

Figura 5: Fissura apresentada no traço 02 do bloco sem resíduos de madeira Fonte: Própria do autor. 


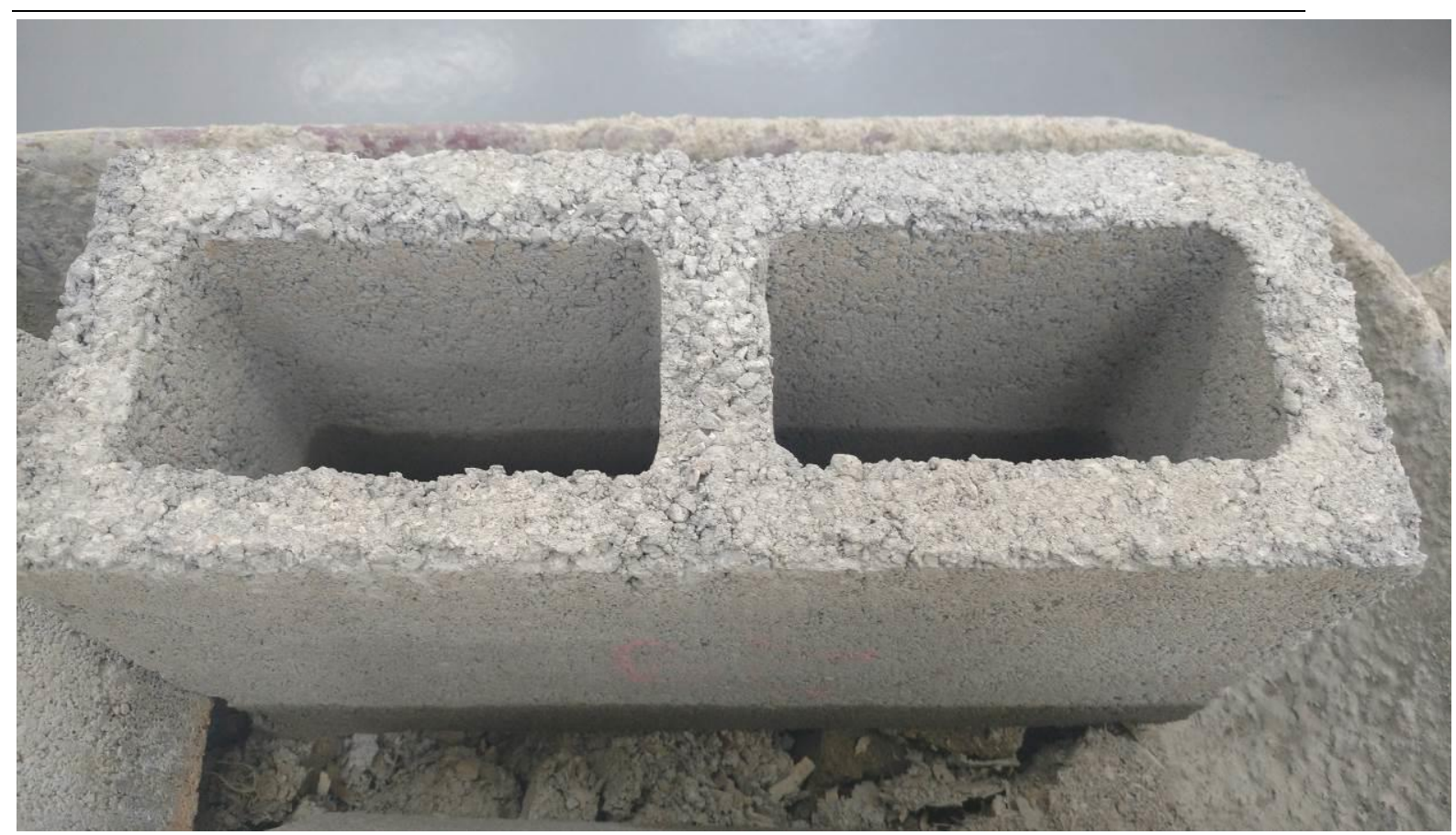

Figura 6: Fissura apresentada no traço 01 do bloco sem resíduo de madeira

Fonte: Própria do autor.

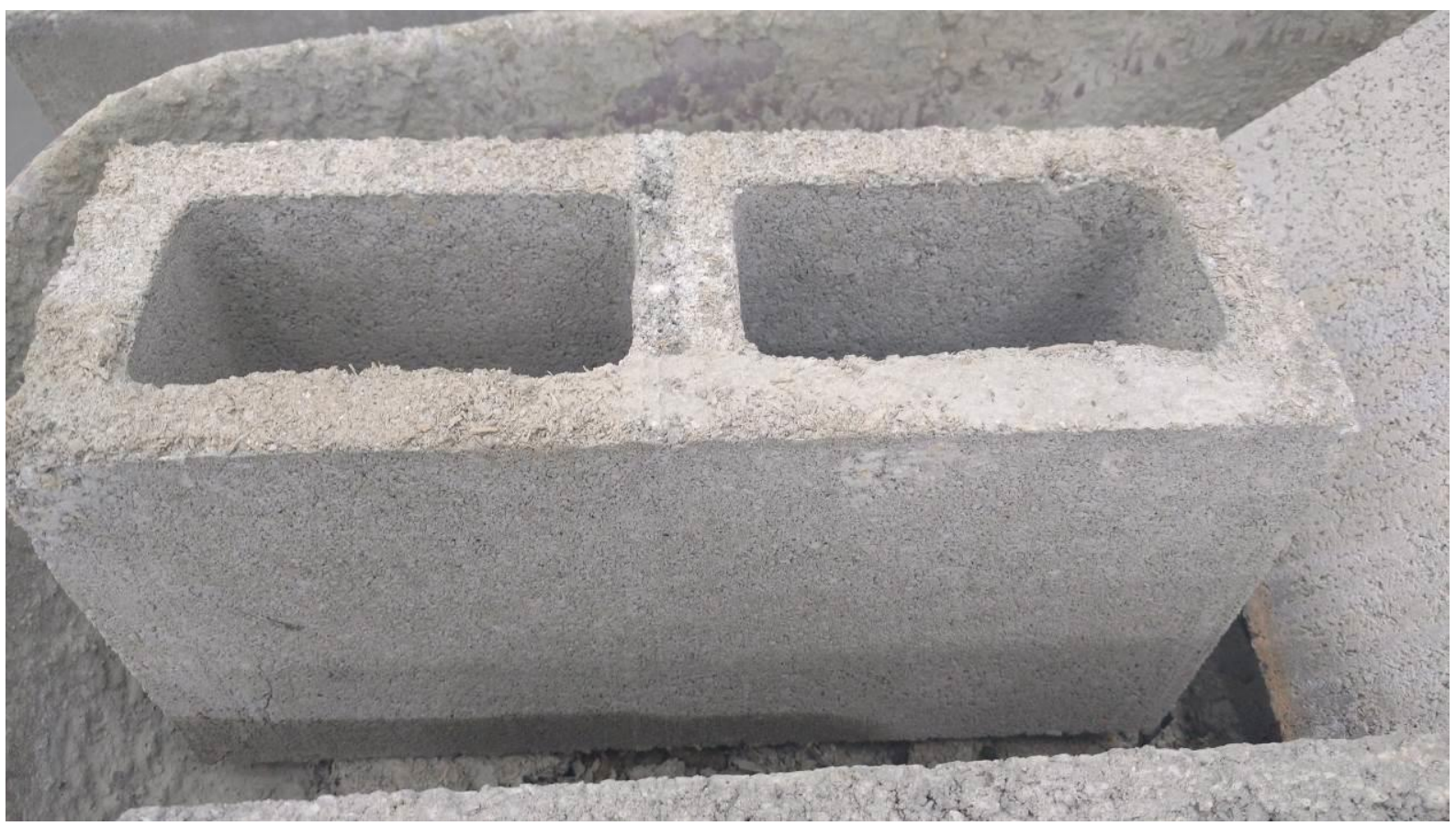

Figura 7: Fissura apresentada no traço 02 do bloco com resíduos de madeira

Fonte: Própria do autor.

Ignis | Caçador | v.6 | n.2 | p. 35-46 | maio/ago. 2017 
Podemos observar claramente as fissuras apresentadas pelo comportamento de cada bloco analisado, somente com presença de fissuras sendo aberturas até 0,5 mm conforme NBR 9575/2010.

\section{CONCLUSÃO}

Analisando os resultados obtidos nestes ensaios, conclui-se que a utilização de resíduos de madeira em fabricação de blocos de concreto é tecnicamente viável, por ser um resíduo facilmente encontrado em grandes quantidades. Conforme os traços apresentados, as duas séries de blocos executados classificaram como função estrutural, mas cuidados devem ser tomados em função ao resíduo de madeira ser uma matéria orgânica apresentando diferenças com o cimento.

Entretanto, a utilização do aditivo na mistura auxiliou em ganhos significativos de resistência, apresentada nas duas séries dos blocos fabricados. De modo comparativo em relação à compactação dos blocos utilizou-se quantidades diferentes de agregados, observando claramente a importância de índices de vazios menores, auxiliando na capacidade de resistência dos blocos.

Percebesse que após a conclusão do ensaio de todos os protótipos, apresentaram somente fissuras superficiais, comparando entre si, a fissura apresentada no bloco com resíduos de madeira foi maior, mas seu resultado permaneceu satisfatório.

Portanto, a utilização de resíduos de madeira possui potencial na fabricação de blocos de concreto, mas deve-se aprofundar em estudos comportamentais destes blocos em um longo prazo, evitando contato excessivo com a umidade.

\section{REFERÊNCIAS}

LIMA, Adauto José Miranda; IWAKIRI, Setsuo. Utilização de resíduos da madeira de Pinus spp. Como substituição ao agregado miúdo na produção de blocos de concreto para alvenaria estrutural. 2014. 12 p. Universidade Federal do Paraná, Santa Maria, 2014.

ASSOCIAÇÃO BRASILEIRA DE NORMAS TÉCNICAS. NBR 6136: Blocos vazados de concreto simples para alvenaria - requisitos. Rio de Janeiro, 2007. 2 p. 
LIMA, Adauto José Miranda; IWAKIRI, Setsuo. Produtos alternativos na produção de blocos para alvenaria estrutural. 2011. 13 p. Universidade Federal do Paraná, Santa Maria, 2011.

NASCIMENTO, Alexandre Miguel do; OLIVEIRA, José Tarcísio da Silva; LUCIA, Ricardo Marius Della. Classificação e propriedades da madeira de pinus e eucalipto. 2001. 8 P. Universidade Federal de Viçosa, Minas Gerais, 2001.

ARAÚJO, Felipe Alves de; MELO, Adan Willian de; CARVALHO, Eduardo de Souza Freitas; BERNARDINO, Fernando Henrique Cabral. Blocos de concreto com pó de serragem. 2013. Universidade Federal de Santa Cecília, São Paulo, 2013.

ASSOCIAÇÃO BRASILEIRA DE NORMAS TÉCNICAS. NBR 12118: Blocos vazados de concreto simples para alvenaria - Método de ensaio. Rio de Janeiro, 2008.

LINTZ, R.C.C; JACINTHO, E.A.P.G.A; PIMENTEL, L.L.; GACHET-BARBOSA, L.A. Study of the reuse of construction residues in concrete employed by blocks manufacture. 2012. Ibracon Structures and materials journal.

SEMPLE, K. E.; EVANS, P. D. Wood-cement composites - Suitability of western Australian malle eucalypt, blue gum and melaleucas. Rural Industries Research and Development Corporation. Kingston: ACT, 2004. 64 p.

DANTAS FILHO, P.F. Contribuição ao estudo para aplicação do pó de serra da madeira em elementos de alvenaria de concreto não estrutural. 2004. Universidade Estadual de Campinas, São Paulo, 2004.

BORGES, Gustavo da Fonseca. Produção de blocos de concreto para vedação: Análise da viabilidade técnico-econômica da utilização de agregados reciclados. 2012. Universidade Federal do Rio Grande do Sul, 2012. 89 p.

ASSOCIAÇÃO BRASILEIRA DE NORMAS TÉCNICAS. NBR 15116: Agregados reciclados de resíduos sólidos da construção civil - Utilização em pavimentação e preparo de concreto sem função estrutural - Requisitos. Rio de Janeiro, 2004.

MEDEIROS, J. S. Alvenaria estrutural não armada de blocos de concreto: Produção de componentes e parâmetros de projeto. 1993. Dissertação (mestrado em engenharia civil) - Escola Politécnica da Universidade de São Paulo, São Paulo, 1993. $24 \mathrm{p}$.

IWAKIRI, S. Avaliação das propriedades físicas e mecânicas de painéis de fibras de média densidade (MDF) produzidos pelas indústrias brasileiras. 2009. Universidade 
Federal do Paraná, Paraná, 2009. 6 p.

SOUZA, J. G.G. Contribuição ao estudo da relação entre propriedades e proporcionamento de blocos de concreto - Aplicação ao uso de entulho como agregado reciclado. 2001. Dissertação (mestrado em Engenharia Civil) Universidade de Brasília, Brasília, 2001. 142 p.

ASSOCIAÇÃO BRASILEIRA DE NORMAS TÉCNICAS. NBR NM 248: Agregado Determinação da composição granulométrica. Rio de Janeiro, 2003.

ASSOCIAÇÃO BRASILEIRA DE NORMAS TÉCNICAS. NBR 9575: ImpermeabilizaçãoSeleção e projeto. Rio de Janeiro, 2010. 